\section{The American Journal of Psychiatry}

\section{August 2018, Volume 175}

\section{Editorials}

707 Prescription Stimulant Use and Misuse: Implications for Responsible Prescribing Practices

Amelia M. Arria, Robert L. DuPont

709 Medication Management for Patients With Borderline Personality Disorder

John G. Gunderson, Lois W. Choi-Kain

712 On the Continued Benefit of Antipsychotics After the First Episode of Schizophrenia

René S. Kahn

714 Do Depression and Stressful Events Cause Premature Aging? Andrew M. McIntosh, Caroline Relton

\section{Clinical case conference}

716 The Tired, Retired, and Recovered Physician: Professional Burnout Versus Major Depressive Disorder Erick Messias, Victoria Flynn

\section{Images in psychiatry}

720 Antonio Vallejo-Nágera (1889-1960) and Juan Antonio Vallejo-Nágera Botas (1926-1990)

Ethan Pearlstein, Javier I. Escobar

\section{APA Presidential addresses}

723 State of Psychiatry in America Anita S. Everett

726 Response to the Presidential Address Altha J. Stewart

Anita S. Everett, M.D., D.F.A.P.A., 144th President, 2017-2018 Brian Hepburn

\section{Reviews and Overviews}

729 Neuroscience of Addiction: Relevance to Prevention and Treatment Nora D. Volkow, Maureen Boyle

\section{New research - articles}

741 Prevalence and Correlates of Prescription Stimulant Use, Misuse, Use Disorders, and Motivations for Misuse Among Adults in the United States

Wilson M. Compton

756 The Clinical Effectiveness and Cost-Effectiveness of Lamotrigine in Borderline Personality Disorder: A Randomized Placebo-Controlled Trial Mike J. Crawford

765 20-Year Nationwide Follow-Up Study on Discontinuation of Antipsychotic Treatment in First-Episode Schizophrenia Jari Tiihonen

$774 \quad$ Epigenetic Aging in Major Depressive Disorder Laura K.M. Han

783 Familiality of Psychiatric Disorders and Risk of Postpartum Psychiatric Episodes: A Population-Based Cohort Study Anna E. Bauer

\title{
BJPsych

\section{Contents}

Cochrane Corner Cholinergic medication for antipsychotic-induced tardive dyskinesia

Irina Tammenmaa-Aho, Rosie Asher, Karla Soares-Weiser \&

Hanna Bergman

Round the corner What is the evidence on cholinergic medication for tardive dyskinesia?

Vishal Bhavsar

Deprescribing antipsychotics: a guide for

clinicians

Swapnil Gupta, John Daniel Cahill \& Rebecca Miller

'Deprescribing' antipsychotics in schizophrenia: witless and

dangerous?

Ann Mortimer
Current understanding of narcissism and narcissistic personality disorder

Jessica Yakeley

Confessions of a liar-detector: I can tell if you're malingering but I can't tell why

Derek K. Tracy

A paradigm shift: relationships in trauma-informed mental health services

Angela Sweeney, Beth Filson, Angela Kennedy, Lucie Collinson \& Steve Gillard

Sexual rights, mental disorder and intellectual disability: principles and law Isabelle Le Gallez, Keith J. B. Rix, Kartina A. Choong \& Helen Dewson 